\title{
Alleviation effects of natural volatile organic compounds from Pinus densiflora and Chamaecyparis obtusa on systemic and pulmonary inflammation
}

\author{
CHANGHWAN AHN ${ }^{1}$, JAE-HWAN LEE $^{1}$, JAE-WOO KIM $^{2}$, MI-JIN PARK $^{2}$, SUNG-SUK LEE $^{2}$ and EUI-BAE JEUNG ${ }^{1}$ \\ ${ }^{1}$ Laboratory of Veterinary Biochemistry and Molecular Biology, Veterinary Medical Center and College of \\ Veterinary Medicine, Chungbuk National University, Cheongju, Chungbuk 28644; \\ ${ }^{2}$ Division of Wood Chemistry and Microbiology, Department of Forest Products, \\ National Institute of Forest Science, Seoul 02455, Republic of Korea
}

Received March 26, 2018; Accepted September 6, 2018

DOI: $10.3892 /$ br.2018.1147

\begin{abstract}
Chamaecyparis obtusa (C. obtusa) and Pinus densiflora ( $P$. densiflora) have been traditionally used as antibiotic, antinociceptive and anti-inflammatory agents in Asian folk medicine. Recent studies have demonstrated antioxidant, antiproliferative and anti-inflammatory effects of $C$. obtusa and $P$. densiflora extracts. In the present study, volatile organic compounds (VOCs) of $C$. obtusa and $P$. densiflora were examined to determine whether they have anti-inflammatory capabilities. To evaluate the anti-inflammatory effects of VOCs of C. obtusa and P. densiflora, lipopolysaccharide (LPS) was administered to the lung by nasal injection and to the whole body by intraperitoneal injection. Alterations in serum immunoglobulin E (IgE) levels and prostaglandin E2 (PgE2) were examined using ELISA. LPS-increased serum $\operatorname{IgE}$ and PgE2 levels were recovered by administration of dexamethasone and VOCs of C. obtusa and P. densiflora. Levels of mRNA expression of inflammatory cytokines were determined in an LPS-induced inflammation mouse model. Reverse transcription-quantitative polymerase chain reaction was used to determine the mRNA expression levels of cyclooxygenase 2 , interleukin (IL)-1 $\beta$, tumor necrosis factor (TNF)- $\alpha$ and IL-13 in peripheral blood mononuclear cells. The expression of all examined cytokine mRNAs increased by LPS was suppressed by dexamethasone and VOCs of C. obtusa and P. densiflora. Similar tendencies were observed in lung tissues and cells obtained via bronchoalveolar lavage. The results of the present study suggested that VOCs of
\end{abstract}

Correspondence to: Professor Eui-Bae Jeung, Laboratory of Veterinary Biochemistry and Molecular Biology, Veterinary Medical Center and College of Veterinary Medicine, Chungbuk National University, Cheongju, Chungbuk 28644, Republic of Korea E-mail: ebjeung@chungbuk.ac.kr

Key words: Chamaecyparis obtusa, Pinus densiflora, inflammation, cytokine, lung
C. obtusa and P. densiflora, through their immunosuppressive activities, may have therapeutic potential in the treatment or prevention of inflammation.

\section{Introduction}

Inflammatory disease has been associated with cytokine and adhesion molecule expression levels. Inflammatory diseases, including asthma and chronic obstructive pulmonary disease are obstructive airway diseases that involve chronic inflammation of the respiratory tract, but the type of inflammation in these two diseases is markedly different with contrasting patterns of inflammatory cell and mediator involvement being reported (1). Allergic asthma is characterized by airway hyper-responsiveness to a variety of specific and non-specific stimuli, including chronic pulmonary eosinophilia, elevated serum immunoglobulin $\mathrm{E}$ ( $\mathrm{IgE}$ ) and excessive airway mucus production (2). IgE is an important mediator of allergic reactions, including allergic asthma, and serves a central role in asthma-related symptoms, airway inflammation and, possibly, airway remodeling (3). The pathophysiology of asthma is thought to be mediated by $\mathrm{CD}^{+} \mathrm{T}$ lymphocytes producing a type 2 cytokine profile (4). When $\operatorname{IgE}$ molecules bind to the surface of an immune cell, that cell is simultaneously sensitized to the specific allergen. The sensitized immune cell immediately exhibits an inflammatory response, including the release of histamine, inducing the early phase of an allergic reaction. Following IgE release, immune cells synthesize other inflammatory molecules, including interleukins (ILs) $(5,6)$.

Chamaecyparis obtusa (C. obtusa) is a species of cypress in the Cupressaceae family. C. obtusa is a slow-growing tree occurring in Japan and South Korea. Essential oil from C. obtusa contains several types of terpenes, including mono-, sesqui- and diterpenes (7). C. obtusa oil has been used as a folk remedy to reduce allergic reactions (8). Several previous studies have reported on the alleviatory effect of $C$. obtusa on allergic dermatitis in a mouse model $(7,9,10)$. In addition, C. obtusa effectively suppresses the levels of serum $\operatorname{IgE}$ and pro-inflammatory cytokines, including ILs, and it affects mast cell appearance $(2,11,12)$. C. obtusa, regarded as an effective 
medicinal plant, contains active terpene compounds that include pharmacologically active molecules.

Pinus densiflora, also known as Korean red pine or Japanese pine, is a species of Pinus in the Pinaceae family. The majority of Pinus spp. occur in the northern hemisphere and certain Pinus spp. have been used in folk medicine for a long time. Pine pollen, bark and leaves are reported to have anti-inflammatory effects $(13,14)$. Pine pollen has demonstrated antioxidant and anti-inflammatory effects (14), while pine bark and its essential oil have been reported to have antinociception and anti-inflammatory effects (13).

Volatile organic compounds (VOCs) have been reported to be associated with the risk of asthmatic and immune responses (15). However, to the best of our knowledge, there have been no reports indicating that exposure to the VOCs of C. obtusa (VOCCo) or P. densiflora (VOCPd) affect asthmatic symptoms, and, in particular, whether they affect IgE and cytokine levels. In addition, the mechanisms underlying the possible hypoallergic effects of VOCCo and VOCPd have not been elucidated. The aim of the present study was to determine whether VOCCo or VOCPd exposure may decrease inflammation and whether one or the two products may be suitable for consideration as a pharmaceutical candidate.

\section{Materials and methods}

Animal experiments. A total of 35 male BALB/c mice (7 mice per group; 7 weeks old; body weight, $30 \mathrm{~g}$ ) were purchased from Koatech Technology Corporation (Pyeongtaek, Republic of Korea), housed in polycarbonate cages with C. obtusa or $P$. densiflora wood panels and corncob bedding, and acclimated in an environmentally controlled room (temperature, $23 \pm 2^{\circ} \mathrm{C}$; relative humidity, $50 \pm 10 \%$; frequent ventilation; and a 12:12 h light:dark cycle). Animal diet were purchased from Purina Petcare (St. Louis, MO, USA), and mice had ad libitum access to animal diet and drinking water. The animal experiments were approved by the Institutional Animal Care and Use Committee of Chungbuk National University (Cheongju, Republic of Korea), and all procedures were performed in accordance with the guide for the care and use of laboratory animals published by the National Institutes of Health (Bethesda, MD, USA).

Lipopolysaccharide (LPS; Sigma-Aldrich; Merck KGaA, Darmstadt, Germany), dissolved in PBS, was used to induce inflammation in the BALB/c mice. LPS was regularly administered via intraperitoneal (i.p.) or intranasal (i.n.) routes for 7 days. The VOC-untreated groups included the vehicle (VE) group, the LPS (LPS $10 \mathrm{mg} / \mathrm{kg}$ ) group and the LPS plus dexamethasone (LPS+DEX; LPS $10 \mathrm{mg} / \mathrm{kg}$, DEX $2.5 \mathrm{mg} / \mathrm{kg}$, i.p.)-treated group (7 mice/group). The VOC-treated groups included the LPS+VOCCo (LPS $10 \mathrm{mg} / \mathrm{kg} ; C$. obtusa wood panel, 1,026 $\mathrm{cm}^{3}$ ) group and the LPS+VOCPd (LPS $10 \mathrm{mg} / \mathrm{kg}$; $P$. densiflora wood panel, 1,026 $\mathrm{cm}^{3}$ ) group. Following the completion of treatment, the mice were sacrificed by ether inhalation, and lung and blood samples were collected for analysis. The IACUC of Chungbuk National University approved all experimental procedures (approval no. CBNUA699-15-07).

Analysis of serum. At the end of the treatment period, blood samples were collected directly from the inferior vena cava using a 1-ml syringe. Serum was obtained by centrifugation at $3,000 \mathrm{x} \mathrm{g}$ for $10 \mathrm{~min}$ at $4^{\circ} \mathrm{C}$ and was stored at $-70^{\circ} \mathrm{C}$ until use. Serum IgE and prostaglandin E2 (PgE2) levels were measured using mouse IgE Ready-Set-Go ELISA kits (cat. no. 50-112-5120; eBioscience; Thermo Fisher Scientific, Inc., Waltham, MA, USA) and the prostaglandin E2 Multispecies Competitive ELISA kit (cat. no. EHPGE2; Thermo Fisher Scientific, Inc.), respectively, according to the manufacturer's protocol.

Isolation of peripheral blood mononuclear cells (PBMCs). Whole blood from each treatment group (VE, LPS, LPS+DEX, LPS+VOCCo and LPS+VOCPd) was used for the extraction of PBMCs. Isolation of PBMCs was performed as previously described (16). In brief, heparinized peripheral blood was drawn from the jugular vein, immediately diluted with an equal volume of PBS without calcium and magnesium, and overlain 1:1 in a Percoll ${ }^{\circledR}$ solution. Following centrifugation at $400 \mathrm{x} \mathrm{g}$ for $45 \mathrm{~min}$ at room temperature, the cells at the interface between the blood plasma and the Percoll ${ }^{\circledR}$ solution were harvested and treated with $0.83 \% \mathrm{NH} 4 \mathrm{Cl}$ in a Tris-base buffer ( $\mathrm{pH}$ 7.2) for $5 \mathrm{~min}$ to lyse the remaining erythrocytes. The resulting PBMCs were prepared for RNA isolation using TRIzol reagent (Invitrogen; Thermo Fisher Scientific, Inc.).

Harvesting of bronchoalveolar fluid. Following euthanasia, bronchoalveolar (BAL) fluid was collected by lavaging lungs with $3 \mathrm{ml}$ Hanks balanced salt solution (Thermo Fisher Scientific, Inc.) through an intratracheal tube. Subsequently, BAL fluid was centrifuged at $17,800 \times \mathrm{g}$ at $\left(4^{\circ} \mathrm{C}\right)$ for $5 \mathrm{~min}$. Following centrifugation, total RNA from BAL fluid was extracted using TRIzol reagent.

Total RNA extraction and reverse transcription quantitative polymerase chain reaction ( $R T-q P C R)$ amplification. Total RNA was extracted from mouse PBMCs, lung tissues and BAL fluid using TRIzol reagent, according to the manufacturer's protocol. RNA concentrations were measured using a microplate spectrophotometer (Epoch; BioTek Instruments, Inc., Winooski, VT, USA) at $260 \mathrm{~nm}$. RNA quality was evaluated by performing electrophoresis on $1 \%$ agarose gel. Total RNA $(1 \mu \mathrm{g})$ was reverse-transcribed into first-strand complementary DNA (cDNA) using Moloney murine leukemia virus reverse transcriptase (Invitrogen; Thermo Fisher Scientific, Inc.) and random primers (9-mer; Takara Bio,Inc., Otsu, Japan), according to the manufacturer's protocol. Each cDNA sample $(1 \mu \mathrm{l})$ was amplified with $10 \mu 12 \mathrm{X} \mathrm{SYBR}{ }^{\circledR}$ Premix Ex Taq ${ }^{\mathrm{TM}}$ (Takara Bio, Inc.) and $10 \mathrm{pmol}$ of each primer according to the manufacturer's protocol. qPCR-based amplification was performed using a 7300 Real-Time PCR system (Applied Biosystems; Thermo Fisher Scientific, Inc.) with the following parameters: Denaturation at $95^{\circ} \mathrm{C}$ for $5 \mathrm{~min}$, followed by 40 cycles of denaturation at $95^{\circ} \mathrm{C}$ for $30 \mathrm{sec}$, annealing at $60^{\circ} \mathrm{C}$ for $30 \mathrm{sec}$ and extension at $72^{\circ} \mathrm{C}$ for $45 \mathrm{sec}$. Relative expression levels in each gene (normalized to that of $18 \mathrm{~S}$ rRNA) were determined using RQ software (version 1.3; Applied Biosystems; Thermo Fisher Scientific, Inc.). Relative expression (R) was calculated using the equation: $\mathrm{R}=2^{-(\Delta \mathrm{Cq} \text { sample- } \Delta \mathrm{Cq} \text { control })}(17)$.

Histopathological analysis. Lung tissue was fixed using $10 \%$ formalin for 2 weeks at room temperature. The tissues were 
embedded in paraffin, cut into sections (5- $\mu \mathrm{m}$ thick) and stained with hematoxylin and eosin (H\&E). Tissue slides were deparaffinized at $65^{\circ} \mathrm{C}$ for $5 \mathrm{~min}$, put into xylene for $20 \mathrm{~min}$. Deparaffinized slides was hydrated in a descending alcohol series $(100,90,75$ and $60 \%$ for $5 \mathrm{~min}$ ) and tap water (10 min). Hydrated slides were stained with hematoxylin for $15 \mathrm{sec}$, washed with tap water for $10 \mathrm{~min}$ and stained with eosin for $30 \mathrm{sec}$ at room temperature. Stained slides were dehydrated in an ascending alcohol series $(60,75,80,90$ and 100\%) and xylene for $5 \mathrm{~min}$. Dehydrated slides were mounted with Canadian balsam. To investigate thickening of the bronchiolar wall, all tissue samples were examined and visualized using a light microscope (BX51; Olympus Corporation, Tokyo, Japan) at X200 magnification. Images was captured using an Olympus DP21 camera, DP controller and DP manager (Olympus Corporation).

Collection of volatile organic compounds in C. obtusa and $P$. densiflora panels. VOCCo and VOCPd were collected by trapping gas emitted from wood panels using a Sibata minipump (MP- 2300 ; Sibata, Saitama, Japan). The composition of the obtained VOCs was analyzed by performing gas chromatography-mass spectrometry (GC-MS; Trace 1310/ISQ-LT; Thermo Fisher Scientific, Inc.). A gas chromatograph uses a column, through which different chemical constituents of a sample pass in a carrier gas at different rates depending on their various chemical and physical properties, and their interaction with a specific column filling, called the stationary phase. The function of the stationary phase in the column is to separate each component, causing each one to exit the column at a different time (retention time). A TR-5MS capillary column (30 cm x $0.25 \mathrm{~mm} \times 0.25 \mu \mathrm{m}$; Thermo Fisher Scientific, Inc.) was used to entrap the gas, and $\mathrm{He}(1 \mathrm{ml} / \mathrm{min}$; $25 \mathrm{psi})$ was used as the carrier gas. The analytes were desorbed in the injection port of the $\mathrm{GC}$ with an inlet temperature of $240^{\circ} \mathrm{C}$. The GC method was initiated with an initial oven temperature of $40^{\circ} \mathrm{C}$ for $5 \mathrm{~min}$. The temperature was then increased at $4^{\circ} \mathrm{C} / \mathrm{min}$ until it reached $200^{\circ} \mathrm{C}$, and was then held at $240^{\circ} \mathrm{C}$ for $10 \mathrm{~min}$ (total run time, $90 \mathrm{~min}$ ). The obtained $\mathrm{VOC}$ compounds were matched with a total ion chromatogram, and the NIST 11 (National Institute of Standards and Technology, Gaithersburg, MA, USA) and W9N08 mass spectral library (Wiley Publishing, Hoboken, NJ, USA). The quantity of each sample was analyzed with a calibration curve using standard chemicals.

Statistical analysis. The results of all experiments are presented as the mean \pm standard deviation. Data were analyzed using one-way analysis of variance and Tukey's post hoc test for multiple comparisons. Data were ranked according to the results of these tests. All statistical analyses were performed using Graphpad software (GraphPad Software, Inc., La Jolla, CA, USA). $\mathrm{P}<0.05$ was considered to indicate a statistically significant difference.

\section{Results}

Effects of VOCCo and VOCPd on serum inflammatory cytokines $I g E$ and $P g E 2$ in LPS-treated mice. For investigation of the anti-inflammatory effects of VOCCo and VOCPd in a BALB/c
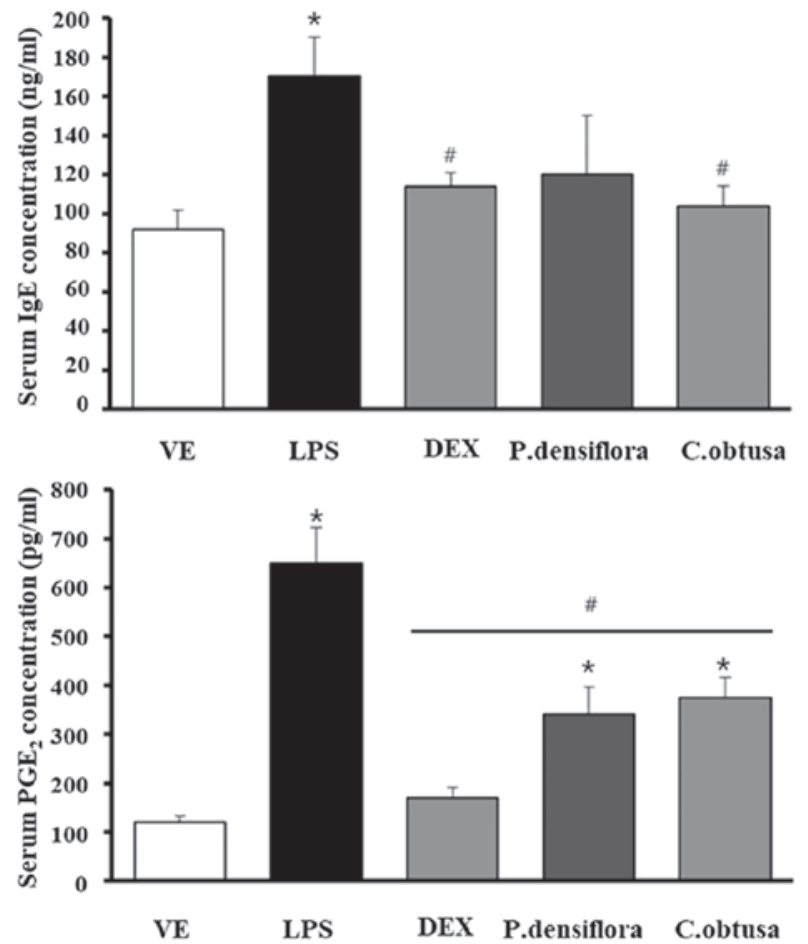

Figure 1. Effects of natural volatile organic compounds of $P$. densiflora and C. obtusa on serum concentrations of IgE and PgE2 in an LPS-induced (i.p.) inflammation model. The serum IgE and PgE2 levels in BALB/c mice were measured at the end of the treatment period using ELISA assays. Groups: VE, vehicle; LPS, negative control; LPS+DEX, positive control; $P$. densiflora and C. obtusa with LPS treatment, experimental groups. Results are expressed as the mean \pm standard deviation. ${ }^{*} \mathrm{P}<0.05$ vs. VE-treated group; ${ }^{\#} \mathrm{P}<0.05$ vs. LPS-treated group. IgE, immunoglobulin E; $\mathrm{PgE}_{2}$, prostaglandin E2; VE, vehicle; LPS, lipopolysaccharide; DEX, dexamethasone.

mouse inflammation model, each mouse was administered with LPS i.p. Compared with the VE group, marked inductions of serum IgE and PgE2 levels were observed in the LPS-treated group. The LPS-elevated serum IgE level was recovered by DEX treatment (Fig. 1). Treatment with VOCCo also resulted in a decrease in the LPS-induced serum IgE level. In addition, the VOCCo and VOCPd treatments reduced PgE2 levels from that in the LPS group. These anti-inflammatory effects on serum $\operatorname{IgE}$ and PgE2 levels indicated that exposure to VOCCo or VOCPd can relieve a systemic inflammatory condition, suggesting that VOCCo and VOCPd could be used for inflammatory relief.

Effects of VOCCo and VOCPd on the expression of inflammatory cytokines in PBMCs in LPS-treated mice. The present study investigated whether VOCCo and VOCPd can inhibit the expression of inflammatory cytokines in PBMCs of mice with LPS-induced inflammation. Expression levels of COX-2, TNF- $\alpha$, IL- $1 \beta$ and IL- 13 mRNA in PBMCs were examined by performing qPCR. Exposure to VOCCo or VOCPd recovered the COX-2, TNF- $\alpha$, IL-1 $\beta$ and IL-13 mRNA expression levels from those in the LPS group (Fig. 2). The aforementioned effects on serum cytokines (Fig. 1) and the changes in the expression of inflammatory cytokines in PBMCs suggested that VOCCo and VOCPd have anti-inflammatory effects.

Effects of VOCCo and VOCPd on the expression of inflammatory cytokines in lung tissue in LPS-treated mice. The present 

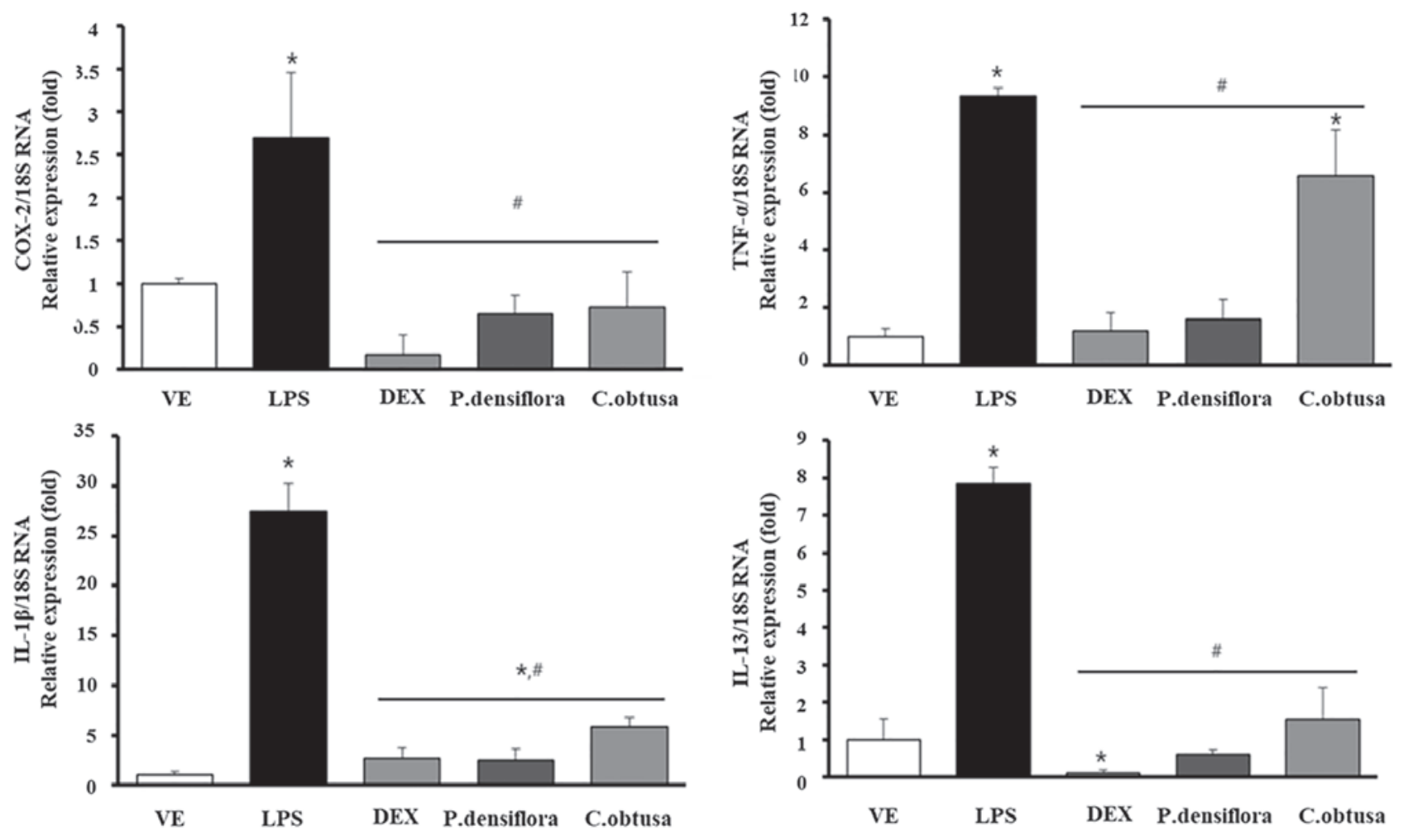

Figure 2. Effects of natural volatile organic compounds of $P$. densiflora and C. obtusa on expression of inflammatory cytokines (COX-2, TNF- $\alpha$, IL-1 $\beta$ and IL-13) in peripheral blood mononuclear cells of LPS-treated mice (i.p.). Groups: VE, vehicle; LPS, negative control; LPS+DEX, positive control; P. densiflora and $C$. obtus $a$ with LPS treatment, experimental groups. Results are expressed as the mean \pm standard deviation. ${ }^{*} \mathrm{P}<0.05$ vs. VE-treated group; ${ }^{\prime \prime} \mathrm{P}<0.05$ vs. LPS treated group. COX-2, cyclooxygenase 2; TNF, tumor necrosis factor; IL, interleukin; LPS, lipopolysaccharide; DEX, dexamethasone; VE, vehicle.

study investigated whether VOCCo and VOCPd can inhibit the expression of pulmonary inflammatory cytokines in lung tissues of mice intranasally treated with LPS. Expression levels of COX-2, TNF- $\alpha$ and NF- $\kappa \mathrm{B}$ mRNA in lung tissue were examined by performing qPCR. Exposure to VOCCo and VOCPd recovered the COX-2, TNF- $\alpha$ and NF- $\kappa$ B mRNA expression levels from those in the LPS-treated group (Fig. 3). The changes in expression of inflammatory cytokines in lung tissue suggested that VOCCo and VOCPd have anti-inflammatory effects in the lung (Fig. 3).

Effects of VOCCo and VOCPd on the expression of inflammatory cytokines in cells in BAL fluid. The present study investigated whether VOCCo and VOCPd treatment would reduce the expression of pulmonary inflammatory cytokines in cells in the BAL fluid of mice intranasally treated with LPS. The number of cells in the BAL fluid was increased by LPS treatment, but treatment with DEX, VOCPd and VOCCo recovered BAL fluid cell numbers (Fig. 4A). In addition, expression levels of COX-2, NF- $\kappa$ B, TNF- $\alpha$, IL- $1 \beta$ and IL-13 mRNA in cells in the BAL fluid were examined by performing qPCR. Exposure to VOCCo and VOCPd recovered the COX-2, TNF- $\alpha$ and $\mathrm{NF}-\kappa \mathrm{B}$ mRNA expression levels from those in the LPS group (Fig. 4). Based on the changes in expression of inflammatory cytokines in cells in the BAL fluid, VOCCo and VOCPd have anti-inflammatory effects on the lung (Fig. 4B-F).

Effects of VOCCo and VOCPd on bronchial thickness in mice with LPS-induced airway inflammation. For observation of changes in bronchial thickness, lung tissues with airway inflammation resulting from i.n. LPS treatment were collected and stained with H\&E. LPS treatment induced acute inflammation of lung tissue and increased bronchial wall thickness, compared with that in the VE group. Bronchial wall thickness was lower in the VOCCo and VOCPd groups than that in the LPS group (Fig. 5). The inflammation alleviatory effects of VOCCo and VOCPd on the lung were similar to that of the positive control, DEX, treatment. These results indicated that VOCCo and VOCPd can reduce LPS-induced airway inflammation in a mouse model.

Contents of natural VOCs from C. obtusa and P. densiflora. In order to identify the effective molecules in natural VOCs from wood for alleviation of systemic/local inflammation, VOCs in the C.obtusa and P. densiflora panels were collected and the quantity was analyzed (Tables I and II) and composition (Tables III and IV) of natural VOCs with GC-MS. $P$. densiflora emit VOCs 1.92-fold more than C. obtusa (2,068.29 ng/l for C. obtusa and 3,975.87 ng/l for P. densiflora for 4 weeks). The total mass of VOCs differ due to the species of wood. P. densiflora emitted more VOCs than C.obtusa. $P$. densiflora and $C$. obtusa emitted $\alpha$-pinene and limonene which has anti-inflammatory effects. These results demonstrated that emitted VOCs from wood are able to alleviate systemic and local airway inflammation.

\section{Discussion}

Various medications, including corticosteroids, calcineurin inhibitors and immune-suppressants, can be used to control 
Table I. Total mass of natural volatile organic compounds obtained from a closed system containing a wood panel (ng/l).

\begin{tabular}{|c|c|c|c|c|c|c|c|c|}
\hline & \multicolumn{4}{|c|}{ C. obtusa } & \multicolumn{4}{|c|}{ P. densiflora } \\
\hline & 1st week & 2nd week & 3rd week & 4th week & 1st week & 2nd week & 3rd week & 4th week \\
\hline 1 & 161.20 & 396.18 & 640.58 & 410.62 & 952.54 & 1150.97 & 633.45 & 822.63 \\
\hline 2 & 186.84 & 966.62 & 247.61 & 536.52 & 1046.3 & 1063.94 & 976.08 & 1073.81 \\
\hline 3 & 306.60 & 1004.80 & 578.40 & 768.92 & 1073.40 & 953.90 & 1261.95 & 918.628 \\
\hline Average & 218.21 & 789.20 & 488.86 & 572.02 & $1,024.08$ & $1,056.27$ & 957.16 & 938.36 \\
\hline
\end{tabular}

C. obtusa, Chamaecyparis obtusa; P. densiflora, Pinus densiflora.
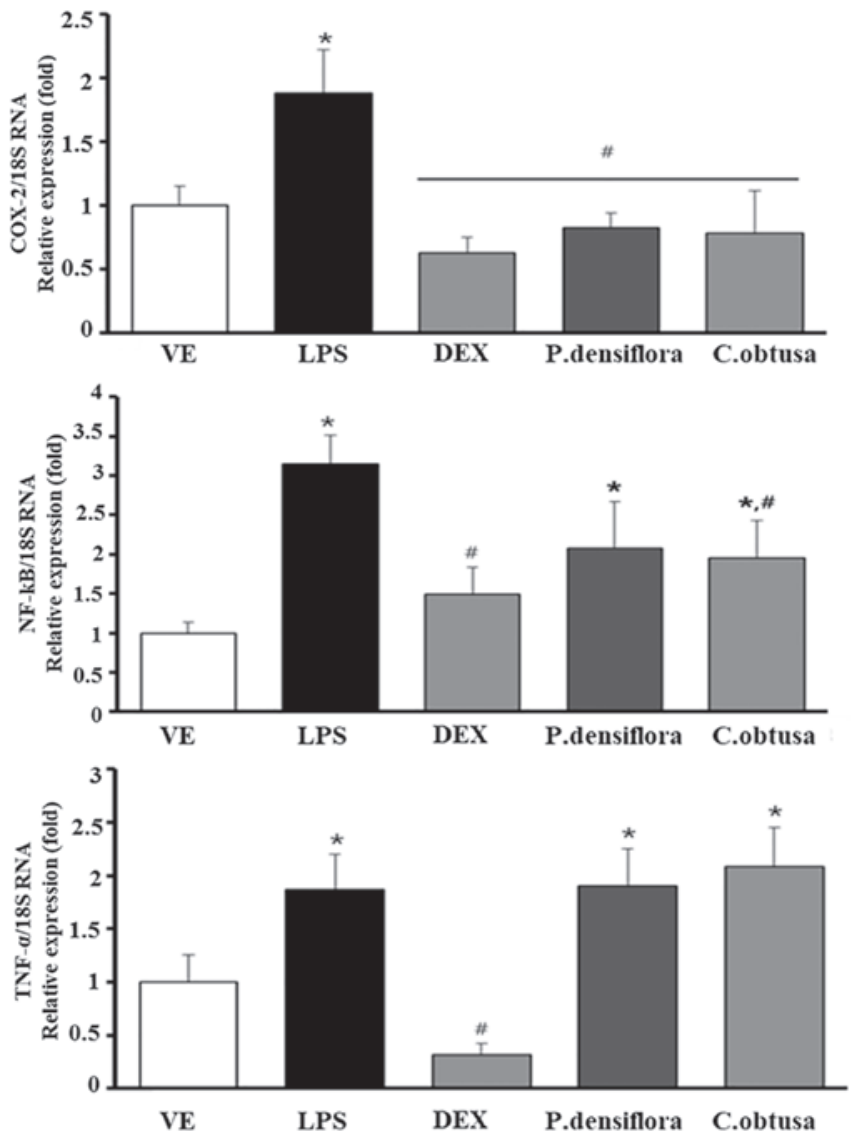

Figure 3. Effects of natural volatile organic compounds of $P$. densiflora and C. obtusa on expression of inflammatory cytokines (COX-2, NF- $\mathrm{kB}$ and TNF- $\alpha$ ) in lung tissue of LPS-treated mice (i.n.). Groups: VE, vehicle; LPS, negative control; LPS+DEX, positive control; P. densiflora and C.obtusa with LPS treatment, experimental groups. Values are expressed as the mean \pm standard deviation. ${ }^{*} \mathrm{P}<0.05$ vs. VE-treated group; ${ }^{*} \mathrm{P}<0.05$ vs. LPS-treated group. COX-2, cyclooxygenase 2; NF, nuclear factor; TNF, tumor necrosis factor LPS, lipopolysaccharide; DEX, dexamethasone; VE, vehicle.

systemic or local inflammation (18). Corticosteroids are the most commonly used medications for the control of inflammation $(18,19)$. However, long-term use of corticosteroids is associated with side effects and drug tolerance within the endocrine system $(19,20)$. To avoid such side effects, prescriptions may indicate a short course of corticosteroid treatment (21). Numerous natural products from plants are being investigated to determine whether they can be used for the treatment of inflammation (22). Recently, herbal-based therapy has been a treatment focus in Asia and Europe due to its efficacy and safety. A wide variety of phenolic substances derived from plants have been reported to have marked antioxidant and anti-inflammatory activities, which may indicate their chemopreventive potential (23). In 2015, Tu Youyou won a Nobel prize for research into the anti-malaria drug artemisinin, which was derived from Artemisia annua (24). Recently, elemol, a compound derived from C. obtusa, was reported to function as an anti-inflammatory reagent, and elemol treatment is expected to prevent the onset of allergic diseases and to ameliorate allergic symptoms $(9,10,25,26)$. In addition, certain VOCs from plants have been reported to have antioxidant and anti-inflammatory activities, and some can directly act as anti-inflammatory reagents (7,27). Although the mechanisms behind certain herbal remedy effects have not been fully elucidated, many such remedies have been reported to have scientific merit and clinical benefit in treating patients $(7,8,25,28-30)$.

The present study investigated the effects of VOCCo and VOCPd in an LPS-induced mouse model of systemic and local inflammation. The LPS-increased serum IgE and PgE2 levels were significantly decreased by application of VOCCo and VOCPd in the LPS-induced systemic inflammation mouse model (Fig. 1). Exposure to VOCCo and VOCPd were revealed to result in successful alleviation of the effect of LPS on inflammation-related cytokines in the blood. Inflammatory cytokine mRNAs (COX-2, TNF- $\alpha$, IL-1b and IL-13) from PBMCs of systemic LPS-treated mice were significantly inhibited by VOCCo and VOCPd treatment (Fig. 2), suggesting that the two VOCs may contribute toward suppression of LPS-stimulated cytotoxic- and helper-T-cell-mediated cytokine expression. Th1 and Th2 responses regulate several immune signaling cascades. Therefore, balancing the Th1/Th2 cytokine responses may be fundamental to the treatment of inflammation (31).

In addition to examining the systemic anti-inflammatory effect of VOCCo and VOCPd treatments, the alleviatory effects of VOCCo and VOCPd were investigated in a local inflammation mouse model created by i.n. LPS spray treatment. The LPS-increased level of the inflammatory T-cell-mediated cytokine COX-2 in lung tissue was significantly decreased by VOCCo and VOCPd treatments. Furthermore, the level of transcription factor for inflammatory cytokine NF- $\kappa \mathrm{B}$, increased by i.n. LPS, was also decreased by treatment with VOCCo and VOCPd. However, the LPS-increased TNF- $\alpha$ level was not decreased by treatment with VOCCo or VOCPd (Fig. 3). In 
Table II. Natural volatile organic compound emissions per unit area $\left(\mathrm{ng} / \mathrm{cm}^{2} / \mathrm{l}\right)$.

\begin{tabular}{|c|c|c|c|c|c|c|c|c|}
\hline & \multicolumn{4}{|c|}{ C. obtusa } & \multicolumn{4}{|c|}{ P. densiflora } \\
\hline & 1st week & 2nd week & 3rd week & 4th week & 1st week & 2nd week & 3rd week & 4th week \\
\hline 1 & 0.11 & 0.26 & 0.43 & 0.30 & 0.47 & 0.56 & 0.31 & 0.40 \\
\hline 2 & 0.12 & 0.65 & 0.17 & 0.39 & 0.51 & 0.52 & 0.47 & 0.52 \\
\hline 3 & 0.20 & 0.67 & 0.39 & 0.56 & 0.53 & 0.46 & 0.61 & 0.44 \\
\hline Average & 0.14 & 0.53 & 0.33 & 0.42 & 0.50 & 0.51 & 0.46 & 0.45 \\
\hline
\end{tabular}

C. obtusa, Chamaecyparis obtusa; P. densiflora, Pinus densiflora.
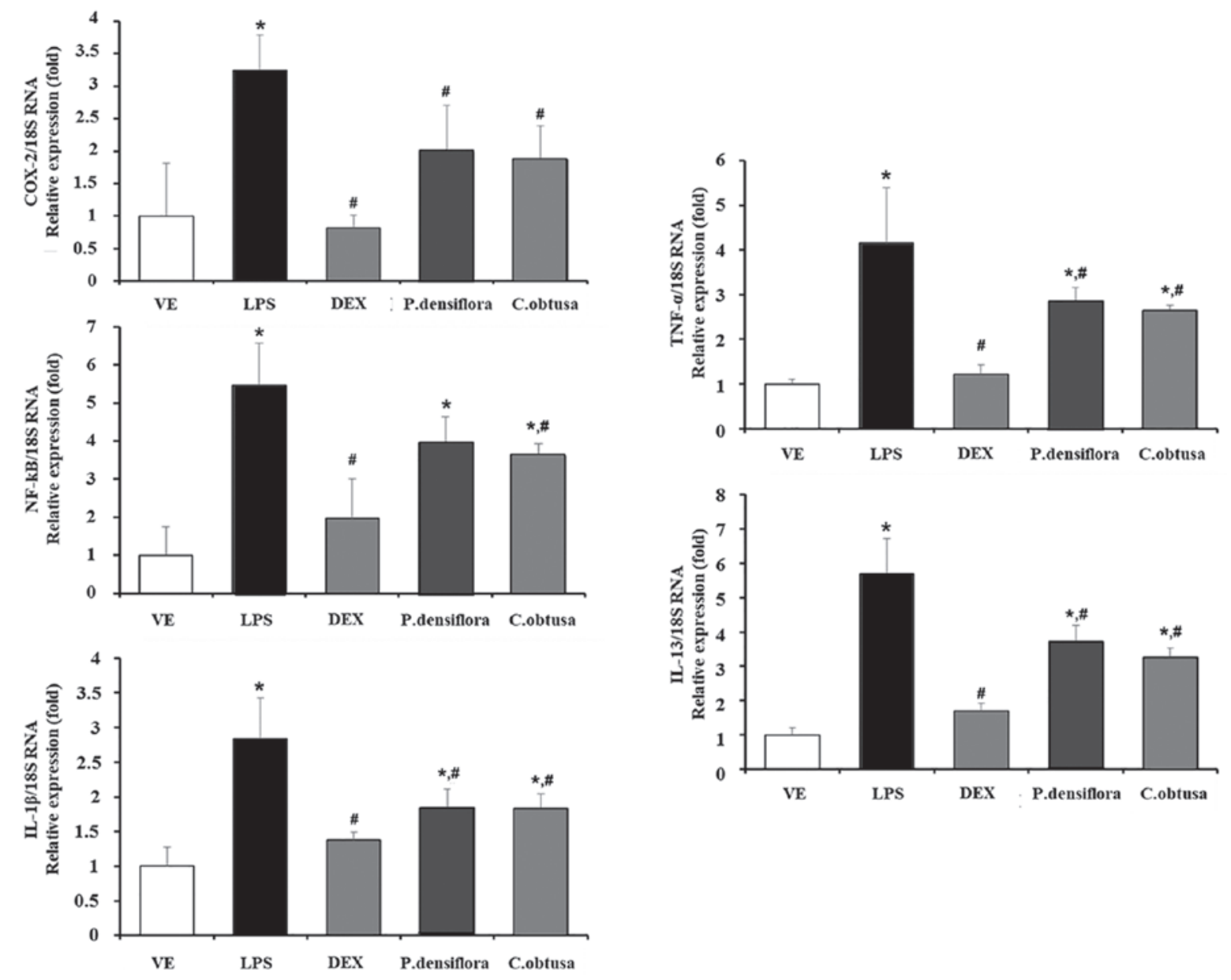

Figure 4. Effects of natural volatile organic compounds of P. densiflora and C. obtusa on cell numbers in BAL fluid and expression of cytokines (COX-2, NF-кB, TNF- $\alpha$, IL-1 $\beta$ and IL-13) in immune cells in BAL fluid of LPS-treated mice (i.n.). Groups: VE, vehicle; LPS, negative control; LPS+DEX, positive control; P. densiflora and C. obtusa with LPS treatment, experimental groups. Values are expressed as the mean \pm standard deviation. "P<0.05 vs. VE-treated group; "P<0.05 vs. LPS-treated group. BAL, bronchoalveolar; COX-2, cyclooxygenase 2; NF, nuclear factor; TNF, tumor necrosis factor; LPS, lipopolysaccharide; DEX, dexamethasone; VE, vehicle.
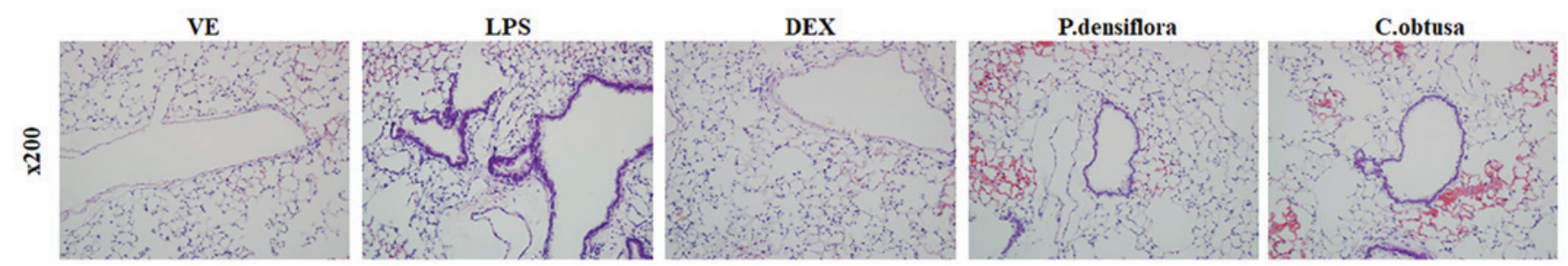

Figure 5. Effects of natural volatile organic compounds of P. densiflora and C. obtusa on airway inflammation. Bronchiole and lung tissues were stained with H\&E. Histological examination of bronchial wall thickening in the LPS-treated group and the LPS plus volatile organic compounds of P. densiflora or C. obtusa treatment groups. (magnification, x200). LPS, lipopolysaccharide; H\&E, hematoxylin and eosin. 
Table III. Natural volatile organic compounds contents in P. densiflora wood panel (gas chromatography-mass spectrometry, ng/l).

\begin{tabular}{|c|c|c|c|c|c|c|}
\hline RT & Chemical & 1st week & 2nd week & 3rd week & 4th week & Average \\
\hline 26.35 & N-carproaldehyde & 117.73 & 173.51 & 280.77 & 188.23 & 190.06 \\
\hline 29.31 & 1-hexanol & 9.58 & 31.51 & 47.89 & 40.70 & 32.42 \\
\hline 29.31 & 2hexen-1-ol & 0.00 & 3.13 & 1.38 & 0.71 & 1.30 \\
\hline 29.74 & 2hexenal & 3.06 & 10.84 & 7.25 & 0.00 & 5.29 \\
\hline 31.38 & heptanal & 15.54 & 64.01 & 60.88 & 39.83 & 45.07 \\
\hline 32.37 & $\alpha$-pinene & 137.82 & 119.08 & 96.04 & 111.66 & 116.15 \\
\hline 33.58 & DL-camphene & 3.86 & 7.85 & 6.18 & 10.40 & 7.07 \\
\hline 33.58 & Camphene & 5.34 & 8.93 & 7.44 & 11.35 & 8.26 \\
\hline 34.04 & 1-Heptanol & 10.41 & 51.73 & 55.09 & 50.02 & 41.81 \\
\hline 34.51 & sabinene & 35.18 & 13.50 & 1.20 & 3.28 & 13.29 \\
\hline 34.52 & $\beta$-Myrcene & 55.04 & 24.37 & 6.72 & 9.54 & 23.92 \\
\hline 35.06 & $\beta$-pinene & 86.76 & 56.49 & 38.50 & 44.70 & 56.61 \\
\hline 36.01 & $\alpha$-phellandrene & 16.72 & 13.59 & 1.75 & 5.34 & 9.35 \\
\hline 36.04 & 3-hexenylester & 0.60 & 0.14 & 0.27 & 0.10 & 0.27 \\
\hline 36.10 & octanal & 2.88 & 29.99 & 36.44 & 16.36 & 21.42 \\
\hline 36.51 & $\alpha$-terpinene & 0.59 & 0.00 & 0.00 & 0.00 & 0.15 \\
\hline 36.62 & benzaldehyde & 11.93 & 21.95 & 9.82 & 34.45 & 19.54 \\
\hline 37.09 & limonene & 51.29 & 55.07 & 30.25 & 46.73 & 45.84 \\
\hline 37.09 & ocimene & 49.72 & 22.29 & 24.14 & 53.72 & 37.47 \\
\hline 37.40 & Meta-cymene & 0.00 & 29.61 & 4.68 & 44.12 & 19.60 \\
\hline 37.40 & Para-cymene & 15.79 & 45.67 & 34.01 & 36.55 & 33.00 \\
\hline 37.47 & $\beta$-phellandrene & 224.82 & 144.78 & 80.22 & 62.50 & 128.08 \\
\hline 37.95 & 1,8-cineole & 0.00 & 0.12 & 1.42 & 2.02 & 0.89 \\
\hline 38.52 & $\gamma$-terpinene & 0.59 & 0.00 & 0.00 & 0.00 & 0.15 \\
\hline 39.61 & benzyl alcohol & 0.06 & 0.00 & 0.00 & 0.00 & 0.01 \\
\hline 40.01 & terpinolene & 12.59 & 7.38 & 2.68 & 4.81 & 6.87 \\
\hline 40.39 & nonanal & 3.69 & 13.74 & 24.52 & 16.61 & 14.64 \\
\hline 41.43 & acetophenone & 0.09 & 0.00 & 0.10 & 0.06 & 0.06 \\
\hline 43.53 & isopulegol & 1.48 & 1.38 & 1.57 & 1.14 & 1.39 \\
\hline 43.69 & pinocarveol & 1.60 & 6.01 & 5.74 & 9.88 & 5.81 \\
\hline 44.65 & 4-Terpineol & 1.88 & 2.67 & 1.47 & 1.84 & 1.97 \\
\hline 44.65 & terpinene-4-ol & 1.14 & 0.43 & 0.00 & 0.00 & 0.39 \\
\hline 44.83 & borneol & 1.05 & 0.00 & 0.00 & 1.38 & 0.61 \\
\hline 45.21 & $\alpha$-terpineol & 8.50 & 8.30 & 2.75 & 6.53 & 6.52 \\
\hline 46.43 & cryptone & 4.92 & 13.47 & 10.82 & 7.95 & 9.29 \\
\hline 46.61 & carveol & 0.00 & 0.53 & 0.00 & 0.00 & 0.13 \\
\hline 47.55 & verbenone & 7.36 & 18.48 & 23.21 & 19.94 & 17.25 \\
\hline 50.25 & Isothymol (carvacrol) & 0.96 & 0.00 & 0.00 & 0.00 & 0.24 \\
\hline 52.10 & $\alpha$-Longipinene & 12.73 & 4.99 & 4.94 & 4.76 & 6.85 \\
\hline 52.71 & geranyl acetate & 0.05 & 0.00 & 0.01 & 0.00 & 0.01 \\
\hline 53.65 & $\beta$-ELEMENE & 0.00 & 0.00 & 1.10 & 2.65 & 0.94 \\
\hline 54.68 & Azulene & 0.02 & 0.00 & 0.00 & 0.00 & 0.00 \\
\hline 55.80 & $\beta$-farnesene & 4.41 & 2.44 & 1.24 & 0.28 & 2.09 \\
\hline 56.71 & caryophyllene & 85.96 & 38.41 & 36.85 & 39.74 & 50.24 \\
\hline 56.75 & $\alpha$-cedrene & 20.29 & 9.88 & 7.86 & 8.51 & 11.63 \\
\hline \multirow[t]{2}{*}{58.97} & Humulene (a-caryophyllene) & 0.08 & 0.00 & 0.00 & 0.00 & 0.02 \\
\hline & Total & 1024.08 & 1056.27 & 957.16 & 938.36 & 993.96 \\
\hline
\end{tabular}

RT, retention time; C. obtusa, Chamaecyparis obtusa; P. densiflora, Pinus densiflora. 
Table IV. Natural volatile organic compound contents in Chamaecyparis obtusa wood panel (gas chromatography-mass spectrometry, ng/l).

\begin{tabular}{|c|c|c|c|c|c|c|}
\hline RT & Chemical & 1st week & 2nd week & 3rd week & 4th week & Average \\
\hline 26.35 & $\mathrm{~N}$-carproaldehyde & 5.09 & 9.63 & 6.41 & 9.04 & 7.54 \\
\hline 29.31 & 1-hexanol & 0.00 & 0.00 & 3.91 & 0.25 & 1.04 \\
\hline 29.31 & 2hexen-1-ol & 0.00 & 0.10 & 0.63 & 0.00 & 0.18 \\
\hline 29.74 & 2hexenal & 0.00 & 9.79 & 0.00 & 3.27 & 3.26 \\
\hline 31.38 & heptanal & 0.00 & 1.36 & 0.08 & 0.81 & 0.56 \\
\hline 32.37 & $\alpha$-pinene & 114.56 & 115.39 & 93.31 & 97.83 & 105.27 \\
\hline 33.58 & DL-camphene & 0.36 & 3.48 & 1.86 & 3.61 & 2.33 \\
\hline 33.58 & Camphene & 1.99 & 4.94 & 3.17 & 5.15 & 3.81 \\
\hline 34.04 & 1-Heptanol & 0.16 & 0.22 & 0.36 & 0.46 & 0.30 \\
\hline 34.51 & sabinene & 1.37 & 15.25 & 1.29 & 2.85 & 5.19 \\
\hline 34.52 & $\beta$-Myrcene & 6.20 & 26.85 & 5.64 & 8.60 & 11.82 \\
\hline 35.06 & $\beta$-pinene & 3.50 & 4.32 & 2.99 & 3.11 & 3.48 \\
\hline 36.62 & benzaldehyde & 0.00 & 0.00 & 0.34 & 0.00 & 0.08 \\
\hline 37.09 & limonene & 18.08 & 118.87 & 56.40 & 67.05 & 65.10 \\
\hline 37.09 & ocimene & 15.43 & 23.17 & 76.54 & 89.41 & 51.14 \\
\hline 37.40 & Meta-cymene & 8.70 & 76.21 & 35.51 & 39.87 & 40.07 \\
\hline 37.40 & Para-cymene & 7.93 & 85.26 & 37.99 & 43.05 & 43.56 \\
\hline 37.47 & $\beta$-phellandrene & 2.04 & 8.95 & 5.65 & 9.62 & 6.57 \\
\hline 38.52 & $\gamma$-terpinene & 0.00 & 0.16 & 0.00 & 0.00 & 0.04 \\
\hline 39.99 & linalool & 0.46 & 0.91 & 0.00 & 0.00 & 0.34 \\
\hline 40.01 & terpinolene & 1.76 & 15.45 & 4.91 & 7.90 & 7.51 \\
\hline 40.39 & nonanal & 0.00 & 0.77 & 0.00 & 0.00 & 0.19 \\
\hline 41.43 & acetophenone & 0.00 & 0.45 & 0.01 & 0.07 & 0.13 \\
\hline 43.53 & isopulegol & 0.70 & 0.51 & 0.69 & 0.92 & 0.71 \\
\hline 43.69 & pinocarveol & 0.00 & 3.39 & 3.50 & 2.70 & 2.40 \\
\hline 44.65 & 4-Terpineol & 4.03 & 29.65 & 17.24 & 20.41 & 17.83 \\
\hline 44.65 & terpinene-4-ol & 3.28 & 48.99 & 24.64 & 32.31 & 27.30 \\
\hline 44.83 & borneol & 3.39 & 38.80 & 19.27 & 25.60 & 21.76 \\
\hline 45.21 & $\alpha$-terpineol & 8.14 & 75.30 & 32.32 & 44.60 & 40.09 \\
\hline 45.93 & myrtenol & 0.00 & 0.00 & 0.00 & 0.36 & 0.09 \\
\hline 46.61 & carveol & 0.00 & 0.81 & 0.00 & 0.00 & 0.20 \\
\hline 47.55 & verbenone & 0.95 & 9.69 & 5.45 & 4.76 & 5.21 \\
\hline 49.19 & bornyl acetate & 1.23 & 18.34 & 10.36 & 9.85 & 9.94 \\
\hline 49.19 & isobornyl acetate & 0.00 & 18.89 & 7.23 & 10.48 & 9.15 \\
\hline 52.10 & $\alpha$-Longipinene & 0.04 & 0.06 & 0.43 & 0.59 & 0.28 \\
\hline 52.71 & geranyl acetate & 0.14 & 0.00 & 0.06 & 0.02 & 0.06 \\
\hline 53.65 & $\beta$-ELEMENE & 8.44 & 23.00 & 29.89 & 24.26 & 21.40 \\
\hline 55.80 & $\beta$-farnesene & 0.00 & 0.00 & 0.00 & 2.27 & 0.57 \\
\hline 56.71 & caryophyllene & 0.00 & 0.00 & 0.41 & 0.67 & 0.27 \\
\hline 57.81 & aromadendrene & 0.04 & 0.25 & 0.36 & 0.25 & 0.22 \\
\hline \multirow[t]{2}{*}{58.97} & Humulene (a-caryophyllene) & 0.19 & 0.00 & 0.00 & 0.00 & 0.05 \\
\hline & Total & 218.22 & 789.20 & 488.86 & 572.02 & 517.07 \\
\hline
\end{tabular}

RT, retention time.

order to provide a more detailed assessment of inflammatory changes associated with local inflammation of mouse lung, cells were collected from the BAL fluid. The number of cells in the BAL fluid was increased by i.n. LPS treatment, but the numbers were decreased following DEX, VOCPd and VOCCo treatments (Fig. 4A). The expression of the cytotoxic- and helper-T-cell-mediated cytokines, COX-2, NF- $\kappa \mathrm{B}, \mathrm{TNF}-\alpha$, IL-1b and IL-13, was also assessed (Fig. 4B-F). VOCCo and 
VOCPd successfully inhibited expression of all examined T-cell-mediated inflammatory cytokines. Furthermore, VOCCo and VOCPd decreased the expression levels of IL-1b and IL-13 more than those of COX-2 and TNF- $\alpha$. The results imply that VOCCo and VOCPd may have local inflammation alleviatory effects that can inhibit helper-T-cell-mediated pathways to a greater extent than their alleviatory effects on cytotoxic-T-cell-mediated pathways. Histopathological assessment of lung tissue via H\&E staining indicated that LPS-induced airway inflammation was alleviated by VOCCo and VOCPd treatment, and that those anti-inflammatory effects were similar to those obtained by DEX treatment, suggesting that the two tested VOCs can reduce airway inflammation.

To initiate elucidation of the two VOCs, gases discharged by wood planks of $C$. obtusa and $P$. densiflora were collected using a Sibata minipump. The quantity of VOCs from the two wood planks were different. Despite the difference in the quantity of VOCs from the wood planks, the effect of the VOCs did not differ as much as the quantity of VOCs. The GC-MS analysis results revealed that VOCCo contains 41 volatile compounds and VOCPd contains 46 volatile compounds. Each of these VOCs contained monoterpenes and sesquiterpenes, with limonene and $\alpha$-pinene being particularly abundant. The main constituents of VOCCo and VOCPd were also similar. Terpenes and sesquiterpenes are well-known anti-inflammatory compounds $(32,33)$, but other compounds, including $\alpha$-terpineol and borneol also have anti-inflammatory effects $(11,12)$. Among the pinene family, $P$.densiflora and C.obtusa emitted $\alpha$-pinene and limonene, which have anti-inflammation effect $(10,34)$. These results demonstrated that emitted VOCs from wood may alleviate systemic and local airway inflammation.

In conclusion, the results of the present study have demonstrated anti-inflammatory effects of VOCCo and VOCPd in systemic and local inflammation mouse models. Based on the results of the present study, VOCCo and VOCPd may contain potent therapeutic compounds that may be beneficial in the treatment of systemic and local inflammations, as well as in the regulation of serum $\operatorname{IgE}$ and $\mathrm{PgE} 2$ levels, and COX-2, TNF- $\alpha$, IL-1b and IL-13 T-cell-derived cytokine levels in inflammatory lesions.

\section{Acknowledgements}

Not applicable.

\section{Funding}

The present study was supported by the National Institute of Forest Science funded by the Korean government (grant no. FP0700-2015-02).

\section{Availability of data and materials}

The datasets analyzed during the current study are available from the corresponding author on reasonable request.

\section{Authors' contributions}

CA, JHL and EBJ were responsible for study design. CA and JHL conducted the study. CA, JHL and EBJ analyzed the animal experiment data. JWK, MJP and SSL analyzed and interpreted the GC/MS data. CA and EBJ drafted the manuscript. EBJ reviewed the integrity of the data analysis. All authors approved the final version of the manuscript.

\section{Ethics approval and consent to participate}

The present study was approved by the IACUC of Chungbuk National University for all experimental procedures (approval no. CBNUA699-15-07).

\section{Patient consent for publication}

Not applicable.

\section{Competing interests}

The authors declare that they have no competing interests.

\section{References}

1. Barnes PJ: Immunology of asthma and chronic obstructive pulmonary disease. Nat Rev Immunol 8: 183-192, 2008.

2. Beasley R, Roche WR, Roberts JA and Holgate ST: Cellular events in the bronchi in mild asthma and after bronchial provocation. Am Rev Respir Dis 139: 806-817, 1989.

3. Holgate S, Casale T, Wenzel S, Bousquet J, Deniz Y and Reisner C: The anti-inflammatory effects of omalizumab confirm the central role of IgE in allergic inflammation. J Allergy Clin Immunol 115: 459-465, 2005.

4. Nakashima T, Hayashi T and Mizuno T: Regulation of the development of asthmatic inflammation by in situ CD4(+)Foxp3 (+) T cells in a mouse model of late allergic asthma. Inflammation 37: 1642-1653, 2014

5. McConnell HM, Watts TH, Weis RM and Brian AA: Supported planar membranes in studies of cell-cell recognition in the immune system. Biochim Biophys Acta 864: 95-106, 1986.

6. Galli SJ, Tsai M and Piliponsky AM: The development of allergic inflammation. Nature 454: 445-454, 2008.

7. Yang H, Ahn C, Choi IG, Choi WS, Park MJ, Lee SS, Choi DH and Jeung EB: Estimation of the environmental effect of natural volatile organic compounds from Chamaecyparis obtusa and their effect on atopic dermatitis-like skin lesions in mice. Mol Med Rep 12: 345-350, 2015.

8. Joo SS, Yoo YM, Ko SH, Choi W, Park MJ, Kang HY, Choi KC, Choi IG and Jeung EB: Effects of essential oil from Chamaecyparis obtusa on the development of atopic dermatitislike skin lesions and the suppression of Th cytokines. J Dermatol Sci 60: 122-125, 2010.

9. An BS, Kang JH, Yang H, Jung EM, Kang HS, Choi IG, Park MJ and Jeung EB: Anti-inflammatory effects of essential oils from Chamaecyparis obtusa via the cyclooxygenase-2 pathway in rats. Mol Med Rep 8: 255-259, 2013.

10. Yang H, Jung EM, Ahn C, Lee GS, Lee SY, Kim SH, Choi IG, Park MJ, Lee SS, Choi DH, et al: Elemol from Chamaecyparis obtusa ameliorates 2,4-dinitrochlorobenzene-induced atopic dermatitis. Int J Mol Med 36: 463-472, 2015.

11. Almeida JR, Souza GR, Silva JC, Saraiva SR, Júnior RG, Quintans JS, Barreto RS, Bonjardim LR, Cavalcanti SC and Quintans LJ Jr: Borneol, a bicyclic monoterpene alcohol, reduces nociceptive behavior and inflammatory response in mice. Sci World J 2013: 808460, 2013.

12. Miguel MG: Antioxidant and anti-inflammatory activities of essential oils: A short review. Molecules 15: 9252-9287, 2010.

13. Ince I, Yesil-Celiktas O, Karabay-Yavasoglu NU and Elgin G: Effects of Pinus brutia bark extract and Pycnogenol in a rat model of carrageenan induced inflammation. Phytomedicine 16: 1101-1104, 2009.

14. Choi EM: Antinociceptive and antiinflammatory activities of pine (Pinus densiflora) pollen extract. Phytother Res 21: 471-475, 2007.

15. Rumchev K, Spickett J, Bulsara M, Phillips M and Stick S: Association of domestic exposure to volatile organic compounds with asthma in young children. Thorax 59: 746-751, 2004. 
16. Shi Y, Zhang P, Zhang L, Osman H, Mohler ER III, Macphee C, Zalewski A, Postle A and Wilensky RL: Role of lipoproteinassociated phospholipase A2 in leukocyte activation and inflammatory responses. Atherosclerosis 191: 54-62, 2007.

17. Jung EM, An BS, Choi KC and Jeung EB: Apoptosis- and endoplasmic reticulum stress-related genes were regulated by estrogen and progesterone in the uteri of calbindin-D $(9 \mathrm{k})$ and -D(28k) knockout mice. J Cell Biochem 113: 194-203, 2012.

18. Boguniewicz M and Leung DY: Atopic dermatitis: A disease of altered skin barrier and immune dysregulation. Immunol Rev 242: 233-246, 2011.

19. Gebben HJ: Topical immunomodulators, such as tacrolimus and pimecrolimus, in the treatment of atopic dermatitis. Ned Tijdschr Geneeskd 149: 1816-1817, 2005 (In Dutch).

20. Dharmage SC, Lowe AJ, Matheson MC, Burgess JA, Allen KJ and Abramson MJ: Atopic dermatitis and the atopic march revisited. Allergy 69: 17-27, 2014.

21. Dereure O, Bessis D, Guillot B and Guilhou JJ: Treatment of bullous pemphigoid by low-dose methotrexate associated with short-term potent topical steroids: An open prospective study of 18 cases. Arch Dermatol 138: 1255-1256, 2002.

22. Abramovits W: Atopic dermatitis. J Am Acad Dermatol 53 (Suppl 1): S86-S93, 2005

23. Surh YJ, Na HK, Lee JY and Keum YS: Molecular mechanisms underlying anti-tumor promoting activities of heat-processed Panax ginseng C.A. Meyer. J Korean Med Sci 16 : S38-S41, 2001

24. Elfawal MA, Towler MJ, Reich NG, Weathers PJ and Rich SM: Dried whole-plant Artemisia annua slows evolution of malaria drug resistance and overcomes resistance to artemisinin. Proc Natl Acad Sci USA 112: 821-826, 2015.

25. Kawai M, Hirano T, Higa S, Arimitsu J, Maruta M, Kuwahara Y, Ohkawara T, Hagihara K, Yamadori T, Shima Y, et al: Flavonoids and related compounds as anti-allergic substances. Allergol Int 56: 113-123, 2007

26. Tan HY, Zhang AL, Chen D, Xue CC and Lenon GB: Chinese herbal medicine for atopic dermatitis: A systematic review. J Am Acad Dermatol 69: 295-304, 2013.
27. Jang HWKM and Lee KG: Antioxidant activity and characterization of volatile extracts of Capsicum annuum L. and Allium spp. Flavour Fragrance J 23: 178-184, 2008

28. Wang W, Zhou Q, Liu L and Zou K: Anti-allergic activity of emodin on IgE-mediated activation in RBL-2H3 cells. Pharmacol Rep 64: 1216-1222, 2012

29. Vender RB: Alternative treatments for atopic dermatitis: A selected review. Skin Therapy Lett 7: 1-5, 2002.

30. Park D, Jeon JH, Kwon SC, Shin S, Jang JY, Jeong HS, Lee DI, Kim YB and Joo SS: Antioxidative activities of white rose flower extract and pharmaceutical advantages of its hexane fraction via free radical scavenging effects. Biochem Cell Biol 87: 943-952, 2009.

31. Heinzel FP, Sadick MD, Holaday BJ, Coffman RL and Locksley RM: Reciprocal expression of interferon gamma or interleukin 4 during the resolution or progression of murine leishmaniasis. Evidence for expansion of distinct helper $\mathrm{T}$ cell subsets. J Exp Med 169: 59-72, 1989.

32. Lyss G, Knorre A, Schmidt TJ, Pahl HL and Merfort I: The anti-inflammatory sesquiterpene lactone helenalin inhibits the transcription factor NF-kappaB by directly targeting p65. J Biol Chem 273: 33508-33516, 1998.

33. Paduch R, Kandefer-Szerszeń M, Trytek M and Fiedurek J: Terpenes: Substances useful in human healthcare. Arch Immunol Ther Exp (Warsz) 55: 315-327, 2007.

34. de Cássia da Silveira e Sá R, Andrade LN and de Sousa DP: A review on anti-inflammatory activity of monoterpenes. Molecules 18: 1227-1254, 2013.

This work is licensed under a Creative Common Attribution-NonCommercial-NoDerivatives 4.0 International (CC BY-NC-ND 4.0) License. 